\title{
Programmed death ligand 1 (PD-L1) expression in parathyroid tumors
}

\author{
Boju Pan ${ }^{1}$, Anqi Wang ${ }^{2}$, Junyi Pang ${ }^{1}$, Yuhan Zhang ${ }^{1}$, Ming Cui ${ }^{3}$, Jian Sun ${ }^{1}$ and Zhiyong Liang ${ }^{1}$ \\ 1'Department of Pathology, Molecular Pathology Research Center, Peking Union Medical College Hospital, Chinese Academy of Medical Sciences \& Peking \\ Union Medical College, Beijing, China \\ ${ }^{2}$ Clinical Biobank, Peking Union Medical College Hospital, Chinese Academy of Medical Sciences \& Peking Union Medical College, Beijing, China \\ ${ }^{3}$ Department of General Surgery, Peking Union Medical College Hospital, Chinese Academy of Medical Sciences \& Peking Union Medical College, \\ Beijing, China
}

Correspondence should be addressed to J Sun or Z Liang: sunjian0720@126.com or liangzhiyong1220@yahoo.com

\begin{abstract}
Introduction: PD-L1 is associated with prognosis and immunotherapeutic response in patients with malignancies. In previous studies, PD-L1 expression was detected in many endocrine tumors. However, the PD-L1 expression status in parathyroid tumors is unknown.

Methods: We included 26 parathyroid carcinoma and 37 adenoma samples, as well as the corresponding patient information. PD-L1 was stained using the FDA-approved PD-L1 IHC 22C3 pharmDx and Ventana PD-L1 (SP263) assays, and staining was assessed by the estimated percentages of positive tumor cells and immune cells, respectively. Results: We classified the PD-L1 expression in the parathyroid tumors into four groups: (0) <1\%, (1) $1-4 \%$, (2) 5-9\% and (3) $\geq 10 \%$ positive. With the SP263 clone, 37 (carcinoma:adenoma = 18:19) samples scored 0, 13 (carcinoma:adenoma =4:9) scored 1, 7 (carcinoma:adenoma = 1:6) scored 2 and 6 (carcinoma:adenoma = 3:3) scored 3. However, in the series of cases using the $22 \mathrm{C} 3$ clone, 45 (carcinoma:adenoma $=20: 25$ ) samples scored 0, 10 (carcinoma: adenoma $=3: 7$ ) scored 1, 5 (carcinoma: adenoma $=1: 4$ ) scored 2, and 3 (carcinoma:adenoma $=2: 1$ ) scored 3 . Concerning tumor-infiltrating immune cells, 57 samples were negative and six were positive with SP263, and 59 were negative and four were positive with 22C3. Moreover, PD-L1 expression was negatively correlated with the $\mathrm{Ki}-67$ index and mitotic rate in parathyroid tumors depending on the different clones. However, the results indicated only moderate consistency between the SP263 and 22C3 clones in parathyroid tumors.

Conclusion: We found deficient PD-L1 expression in the majority of parathyroid tumors. However, the PD-L1 expression score in parathyroid tumors depended greatly on the antibody clone used.
\end{abstract}

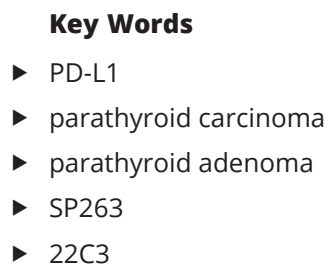

Endocrine Connections (2019) 8, 887-897

\section{Introduction}

Programmed death-1 (PD-1) and its ligand PD-L1 have been described as key regulators of $\mathrm{T}$ cell responses, and the interaction between PD-1 on T-cells and PD-L1 on cancer cells provides a mechanism for cancer cells to evade proper recognition as foreign and thus escape attack by the immune system (1). Indeed, PD-L1 expression levels have been correlated with clinical outcome (1). Additionally, as the development of PD-1 inhibitors to treat malignancies has progressed, a series of drugs, including nivolumab and pembrolizumab, have been approved by the FDA to treat melanoma (2), pulmonary carcinoma $(3,4)$ and even all solid tumors that are mismatch repair-deficient

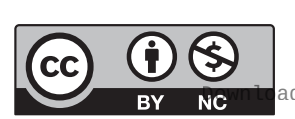

This work is licensed under a Creative Commons Attribution-NonCommercial 4.0 International License. ded from Bioscientifica.com at 04/26/2023 01:41:36PM 
(dMMR)/or have high-level microsatellite instability (MSI-H) (5). Encouragingly, according to current clinical trials, PD-1 inhibitors combined with chemotherapy are proven to be more effective than conventional chemotherapy for treating pulmonary cancer, which challenges traditional therapeutic recommendations as well as the NCCN guidelines (6). Moreover, for patients in whom more than $50 \%$ of tumor cells are positive for PD-L1 expression, PD-1 inhibitors can even be the firstline treatment $(7,8)$. As mentioned above, PD-L1 is not only a marker for diagnosis and prognosis prediction but also an index for the immunotherapy response. Four types of PD-L1 antibodies and their corresponding evaluation criteria have been approved by the FDA for clinical PD-L1 evaluation: the PD-L1 IHC 22C3 pharmDx assay, PD-L1 28-8 pharmDx assay, Ventana PD-L1 (SP142) assay and Ventana PD-L1 (SP263) assay $(9,10)$.

PD-L1 expression has been detected in many endocrine tumors, including pituitary tumors (11), papillary thyroid carcinomas (12, 13), adrenocortical carcinomas (14), pheochromocytomas (15) and gastroenteropancreatic neuroendocrine neoplasms (16). But PD-L1 expression was significantly different among these tumor types. No studies have investigated PD-L1 expression in parathyroid adenoma and carcinoma, because of their low morbidity. However, evaluation of prognosis and the immunotherapy response is necessary for patients with hyperparathyroidism. Consequently, we used the FDA-approved PD-L1 IHC 22C3 pharmDx assay and the Ventana PD-L1 (SP263) assay to examine and evaluate PD-L1 expression in these parathyroid tumors.

\section{Materials and methods}

\section{Tumor samples and patient information}

In this analysis, we included 26 parathyroid carcinoma samples, including two primary foci without invasion, 15 primary foci with invasion and 9 metastatic foci, from 22 patients, as well as 37 parathyroid adenoma samples from different individuals. All patients underwent surgical treatment at Peking Union Medical College Hospital from 2002 to 2017, and the samples were formalin-fixed and paraffin-embedded as appropriate. The baseline and follow-up information for the patients was collected from our database, and the last follow-up was in May 2018. We reviewed all slices of the parathyroid carcinoma patients and confirmed that the diagnosis was appropriate (tumors with an invasive growth involving adjacent structures or distant metastasis; two samples without an invasive growth pattern were included depending on the diagnosis of carcinoma in the other samples of the same patient). Moreover, we randomly selected one ID number among the thousands of adenoma patients and rechecked the follow-up of the following 40 patients. We ensured the inclusion of patients without recurrence or metastasis in at least 2 years. According to the follow-up information, all of these patients, except for three patients without complete follow-up information, were included. Our research was a retrospective study and all the samples were from resections for parathyroid tumor treatment. The research will not affect any clinical decision or safety of the patients. Therefore, ethical committee approval was not required for our research. At the same time, each patient has consent after full explanation of the purpose and nature of all procedures used.

\section{Immunohistochemistry}

Each slide set of all cases was stained using the PD-L1 IHC 22C3 pharmDx assay purchased from Dako and the Ventana PD-L1 (SP263) assay purchased from Ventana (Tucson, AZ, USA) in accordance with their respective protocols detailed in the product inserts and autostainer manuals (Dako Autostainer Link48 for 22C3 and Ventana BenchMark Ultra for SP263). Immunohistochemical staining for MMR-related proteins, including MLH1 (clone ES05, Dako, Agilent), MSH2 (clone FE11, Dako, Agilent), MSH6 (clone EP49, Dako, Agilent) and PMS2 (clone EP51, Dako, Agilent), was performed on the Dako Autostainer Link48. In addition, Ki-67 was stained with a monoclonal antibody against Ki-67 (Ki67) (ZSGB-BIO, Beijing, China) using the Dako Autostainer Link48.

\section{PD-L1 staining evaluation}

For the evaluation of PD-L1 staining, positive tumor cell staining was defined as either partial or complete membranous staining at any intensity. Positive immune cell staining was defined as either cytoplasmic or membranous staining of any intensity. Normal parathyroid cells and necrotic cells were excluded from the evaluation. Tumor cell staining was assessed by the estimated percentage of positive tumor cells, and the samples were designated as 'positive' cases if $\geq 1 \%$ of the tumor cells were stained. In addition, immune cell staining was assessed by initially reviewing the entire tumor area and determining the percentage of the tumor area occupied by immune cells (ICP). Next, the percentage of immune cells demonstrating any pattern of PD-L1 expression (IC+) within the tumor

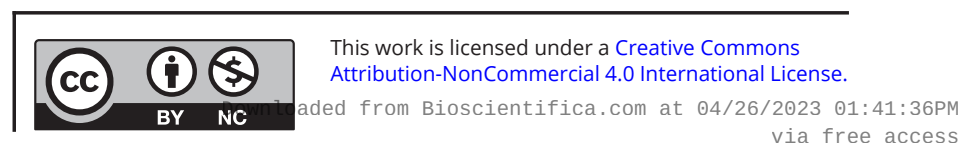


area was visually estimated. In cases where the ICP was $\leq 1 \%$, IC+ staining was scored as either $0,<100$ or $100 \%$ due to the difficulties in estimating the percent staining in small volumes of immune cells present in low quantities. According to the PD-L1 evaluation criteria for urothelial carcinoma (9), cases with ICP $>1 \%$ and IC $+\geq 25 \%$ or ICP $\leq 1 \%$ and $\mathrm{IC}+=100 \%$ were considered IC-positive cases. All pathologists were trained and received certificates for standard PD-L1 evaluation from Roche and Agilent training programs.

\section{Statistical analyses}

The comparison between the antibody clones was conducted by kappa analysis and intraclass correlation coefficient (ICC) analysis. Furthermore, the MannWhitney $U$ test, the chi-square test and Fisher's test were used to compare PD-L1 staining between the parathyroid carcinoma cells and adenoma cells, as well as with the other clinical features. The log-rank test was used to evaluate the survival analysis. SPSS software, version 25.0 (IBM Corporation) was used for the statistical analyses. $P<0.05$ was considered statistically significant.

\section{Results}

\section{Clinical features of parathyroid tumors}

Of the parathyroid carcinoma patients, 13 were male and 9 were female ( $\mathrm{F}: \mathrm{M}=0.69: 1)$, ranging in age from 24 to 76 years (mean, 43.3 years). The tumor sizes were variable, ranging from 0.2 to $4 \mathrm{~cm}$ (mean, $1.84 \mathrm{~cm}$ ). The mitotic rate in different samples was inconsistent, ranging from $<1$ to $>10$ mitoses/10 high-power fields (HPF). Additionally, the Ki-67 index ranged from 1 to $20 \%$ (mean, $8 \%$ ). In addition, the atypical mitosis, necrosis and nucleolus in the carcinoma samples were variable. Almost all the patients in our study were alive; only two of the patients were nonsurviving, but they lived more than 10 years after the first resection. However, only three patients did not exhibit relapse and metastasis, and three patients developed metastasis after resection of the primary foci. The details of the carcinoma patients are shown in Table 1.

Regarding the clinical features of the adenoma patients, 11 of these patients were male and 26 were female (F:M=2.36:1), and their ages ranged from 24 to 77 years (mean, 54.5 years). The diameter of the adenomas ranged from 1 to $4.5 \mathrm{~cm}$ (mean, $1.84 \mathrm{~cm}$ ), and fewer mitoses were seen in the adenomas than in the carcinomas. The Ki-67 index in the adenomas ranged from 1 to $10 \%$ (mean, 2\%). In addition, none of the tumors exhibited necrosis or atypical mitosis, and prominent nucleoli were seen in a sample from only one patient. The details of the adenoma patients are shown in Table 2.

\section{MMR status of parathyroid tumors}

According to previous studies (17), the MMR status is related to PD-L1 expression. Therefore, we evaluated the MMR status of all cases by examining MMR-related proteins (MLH-1, MSH-2, MSH-6 and PMS-2). The results demonstrated that all cases were MMR proficient (pMMR).

\section{PD-L1 expression using the SP263 clone and the relationship between PD-L1 expression and the clinical features of parathyroid tumors}

Of the 26 carcinoma samples, 8 (30.8\%) were considered positive and $18(69.2 \%)$ were negative. Of the 37 adenoma cases, $18(48.6 \%)$ were positive and 19 cases (51.3\%) were negative (Fig. 1). Additionally, according to the PD-L1 expression in the parathyroid tumors and the results of previous studies $(3,4)$, we classified the results into four groups: (0) <1\% (Fig. 2A), (1) 1-4\% (Fig. 2B), (2) 5-9\% (Fig. 2C) and (3) $\geq 10 \%$ (Fig. 2D). Of the carcinoma samples, 18 (69.2\%) scored 0, 4 (15.4\%) scored 1, 1 (3.8\%) scored 2 and $3(11.5 \%)$ scored 3 . Additionally, of the adenoma samples, 19 (51.3\%) scored 0, 9 (24.3\%) scored 1, 6 (16.2\%) scored 2 and 3 (8.1\%) scored 3 (Fig. 1).

In addition to evaluating tumor cells, we evaluated PD-L1 expression in tumor-infiltrating immune cells. First, we determined the ICP of all the samples. No sample had an ICP of more than 5\%, and the ICP of the majority was $\leq 1 \%$. Moreover, only seven carcinoma and four adenoma samples had an ICP of 5\% (Fig. 3A). Additionally, the percentage of PD-L1 positive immune cells (IC+) ranged from 0-50\% when the SP263 clone was used (Fig. 3B). A total of 57 samples were IC negative (carcinoma:adenoma $=22: 35$ ) and 6 were IC positive (carcinoma:adenoma $=4: 2$ ). Additionally, the IC + in 50 samples was $0 \%$.

Furthermore, the relationship between PD-L1 expression and clinical features is shown in Table 3. This analysis demonstrated that tumor cell PD-L1 expression was consistent between parathyroid carcinoma and adenoma $(P=0.106)$. In addition, PD-L1 expression was not associated with age $(P=0.914)$, sex $(P=0.342)$, tumor size $(P=0.050)$, necrosis $(P=1.000)$, mitosis $(P=0.762)$,
This work is licensed under a Creative Commons Attribution-NonCommercial 4.0 International License. ded from Bioscientifica.com at 04/26/2023 01:41:36PM via free access 


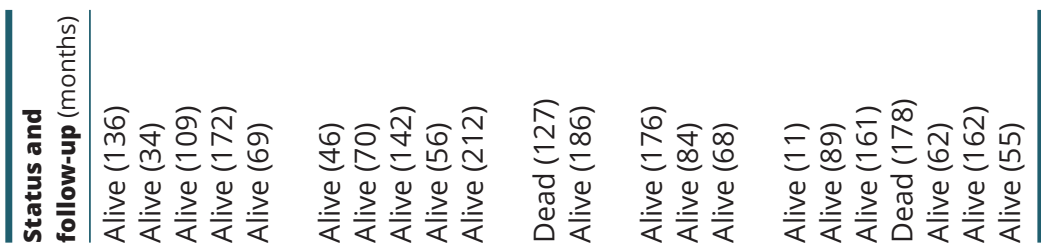

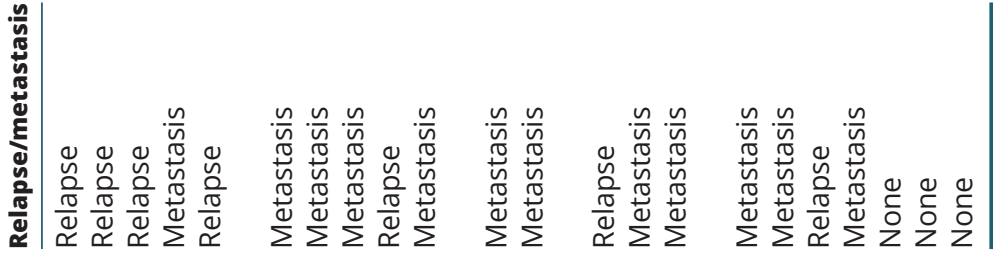

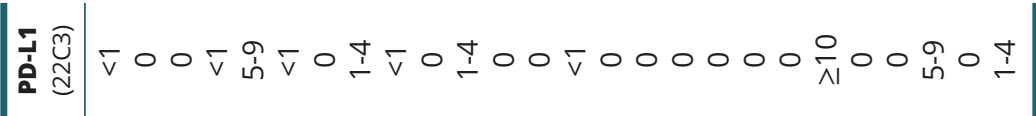

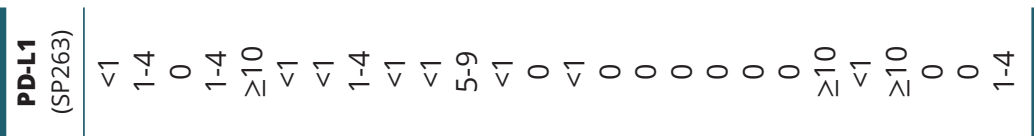

$\frac{\stackrel{n}{\frac{n}{2}} \mid}{\frac{d}{2}} \mid>>>z z z z z z z z z z z>>z>z>z>z z z$

竞

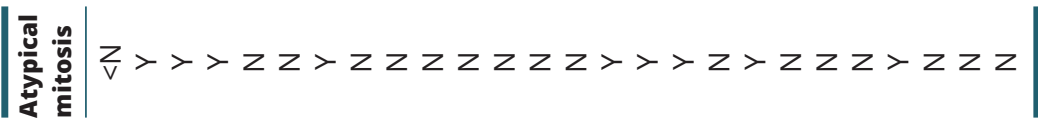

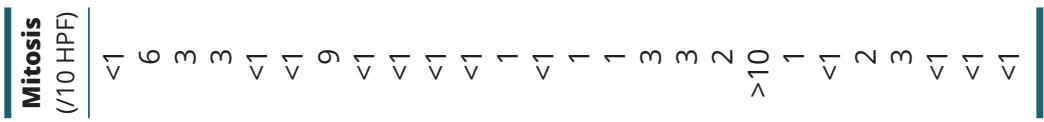

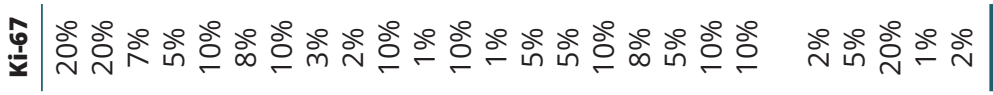

离

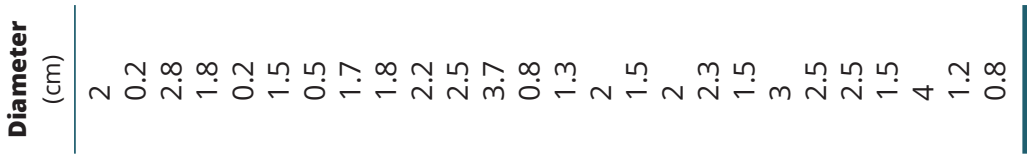

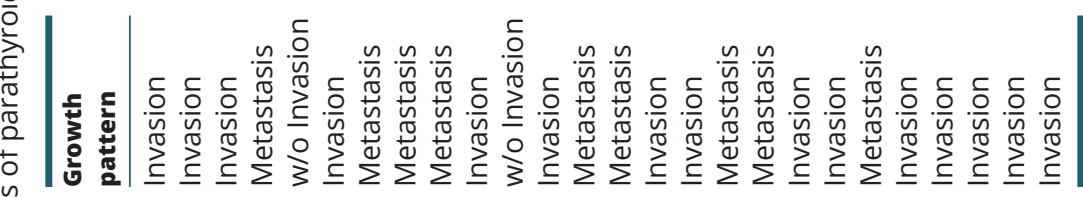

n

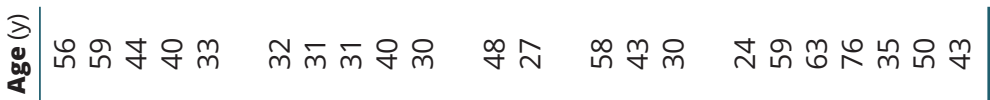

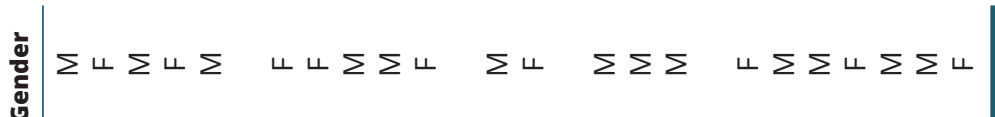

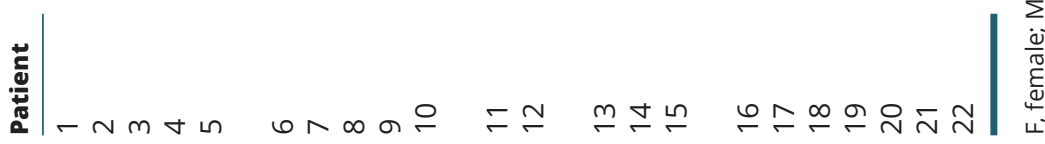


Table 2 The clinical features of parathyroid adenoma.

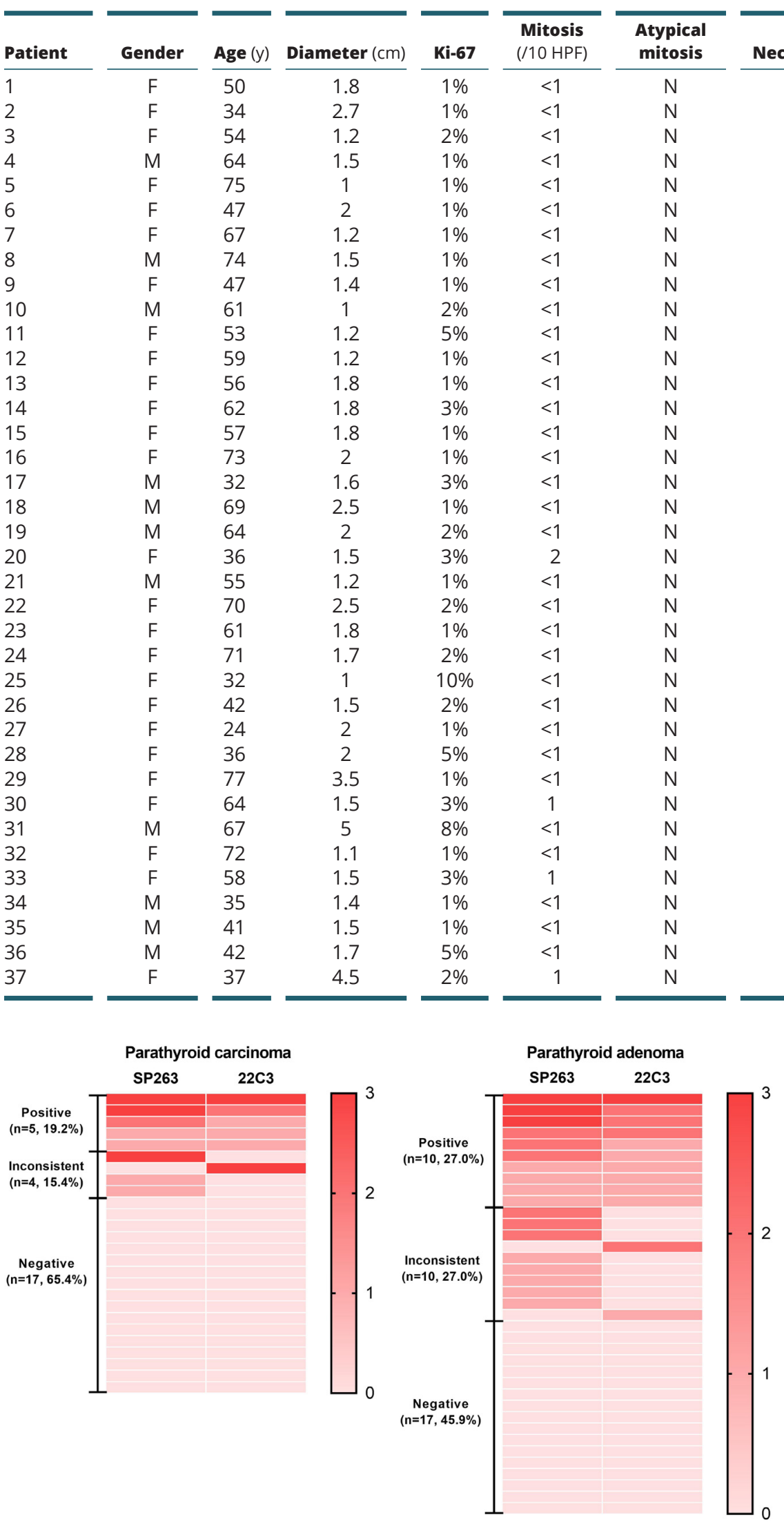

Figure 1

Heat map comparing staining results with the PD-L1 SP263 and 22C3 antibody clones in parathyroid carcinoma and adenoma tissues. https://ec.bioscientifica.com

https://doi.org/10.1530/EC-19-0163 (c) 2019 The authors Published by Bioscientifica Ltd

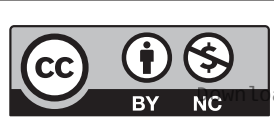

This work is licensed under a Creative Commons Attribution-NonCommercial 4.0 International License. 

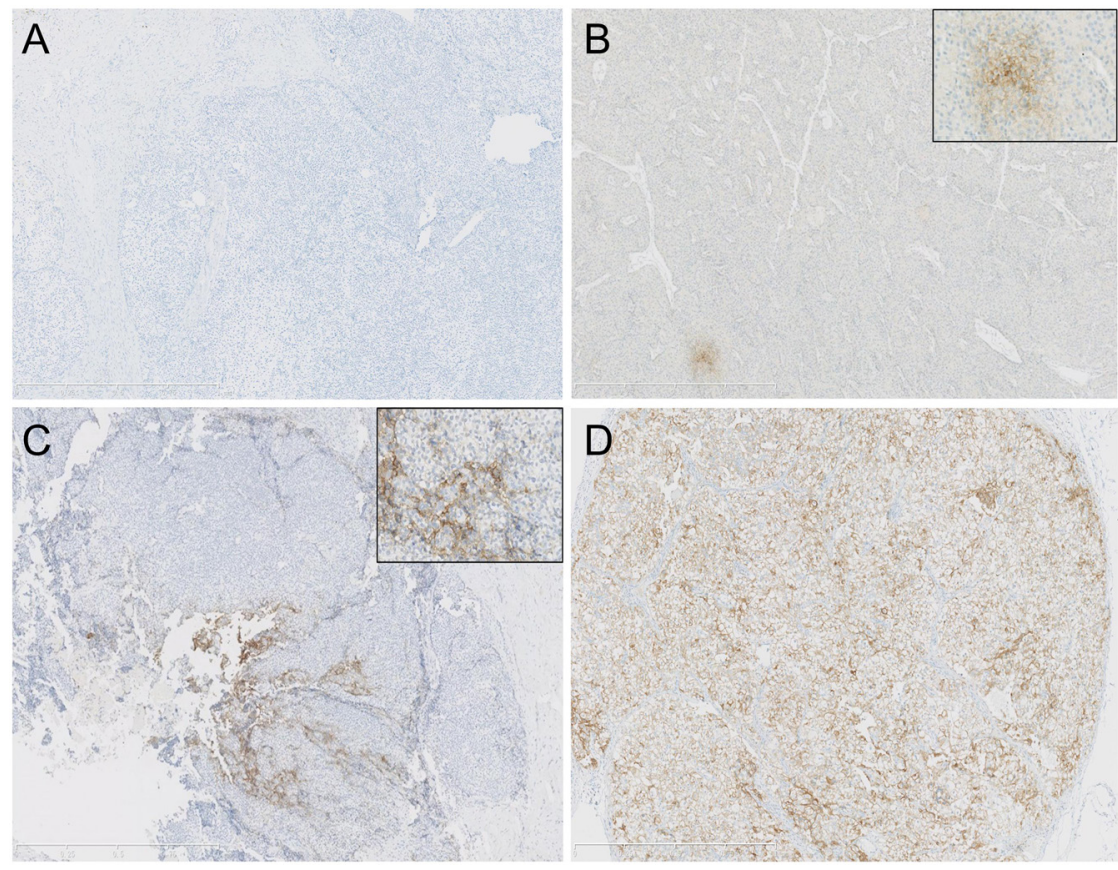

\section{Figure 2}

PD-L1 staining of parathyroid tumors and the different percentages of positive tumor cells, including < $1 \%(A, 50 \times), 1-4 \%$ (B, 50x. Inset: positive area, 400×), 5-9\% (C, 50×. Inset: positive area, 400×) and $\geq 10 \%(D, 50 \times)$.

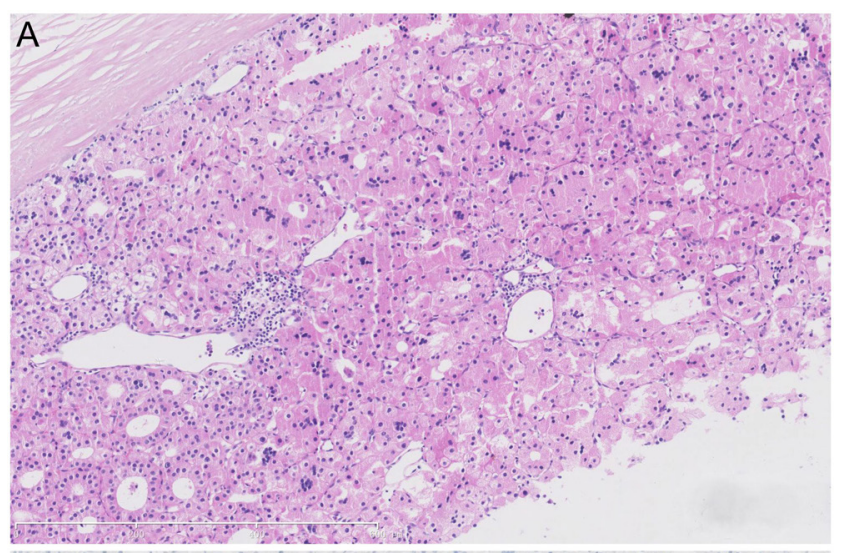

B

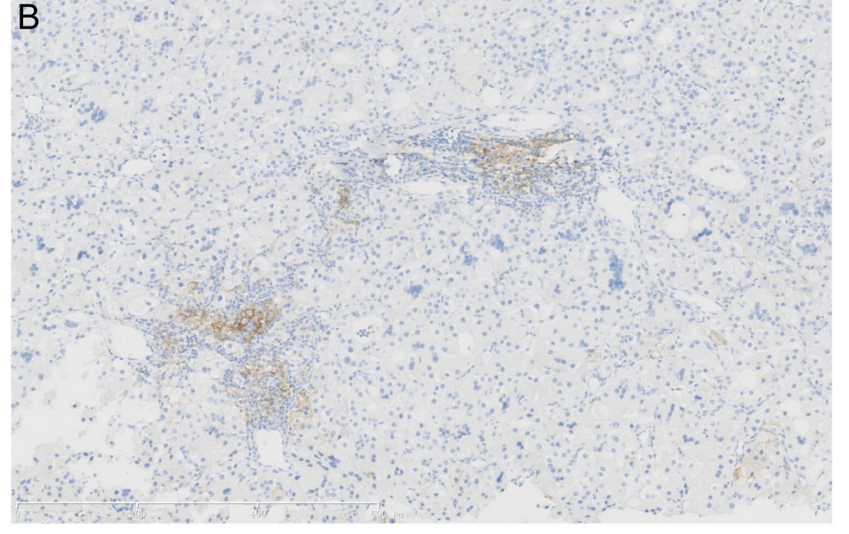

\section{Figure 3}

Hematoxylin and eosin staining of a 5\% ICP case (A, 100x). The corresponding PD-L1 staining showed an IC+ of 50\% $(B, 100 \times)$. atypical mitosis $(P=0.725)$, nucleoli $(P=1.000)$ or ICP $(P=0.725)$ in the total patient cohort or with survival $(P=0.960)$ in the carcinoma patient cohort. However, PD-L1 expression was negatively correlated with the Ki-67 index $(P=0.043)$. Moreover, the results revealed that immune cell PD-L1 expression was not associated with any clinical feature or with survival $(P=0.739)$ in parathyroid tumor patients (Table 4).

\section{PD-L1 expression using the $22 \mathrm{C} 3$ clone and the relationship between PD-L1 expression and the clinical features of parathyroid tumors}

Of the 26 carcinoma samples, 6 (23.1\%) were positive and $20(76.9 \%)$ were negative. Of the 37 adenoma cases, 12 (32.4\%) were positive and 25 (67.6\%) were negative (Fig. 1). In addition, 20 (76.9\%) carcinoma samples scored $0,3(11.5 \%)$ scored 1, 1 (3.8\%) scored 2 and 2 (7.7\%) scored 3. Moreover, 25 (67.6\%) adenoma samples scored 0,7 (18.9\%) scored 1, 4 (10.8\%) scored 2, and 1 (2.7\%) scored 3 (Fig. 1). As with the SP263 clone, the percentage of PD-L1-positive immune cells ranged from 0 to $50 \%$ using the $22 \mathrm{C} 3$ clone. A total of 59 of the samples were IC-negative (carcinoma:adenoma $=24: 35$ ) and 4 were IC-positive (carcinoma:adenoma=2:2). Additionally, the IC+ in 52 samples was $0 \%$.

Regarding clinical features, similar to the above result for the SP263 clone, tumor cell PD-L1 expression https://ec.bioscientifica.com https://doi.org/10.1530/EC-19-0163 (c) 2019 The authors Published by Bioscientifica Ltd
This work is licensed under a Creative Commons Attribution-NonCommercial 4.0 International License. ded from Bioscientifica.com at 04/26/2023 01:41:36PM 
Table 3 The correlation between clinical features and tumor cells PD-L1 expression.

\begin{tabular}{|c|c|c|c|c|c|c|c|}
\hline & \multirow[b]{2}{*}{ Total } & \multicolumn{2}{|c|}{ SP263 (tumor cells) } & \multirow[b]{2}{*}{$P$ value } & \multicolumn{2}{|c|}{22 C3 (tumor cells) } & \multirow[b]{2}{*}{$P$ value } \\
\hline & & Positive & Negative & & Positive & Negative & \\
\hline \multicolumn{8}{|l|}{ Gender } \\
\hline M & 24 & 8 & 16 & \multirow{2}{*}{0.342} & 8 & 16 & \multirow{2}{*}{0.374} \\
\hline $\mathrm{F}$ & 35 & 16 & 19 & & 8 & 27 & \\
\hline \multicolumn{8}{|l|}{ Age } \\
\hline$\leq 50 \mathrm{y}$ & 30 & 12 & 18 & \multirow[t]{2}{*}{0.914} & 8 & 22 & \multirow[t]{2}{*}{0.937} \\
\hline$>50 y$ & 29 & 12 & 17 & & 8 & 21 & \\
\hline \multicolumn{8}{|l|}{ Diameter } \\
\hline$\leq 1.8 \mathrm{~cm}$ & 38 & 19 & 19 & \multirow[t]{2}{*}{0.050} & 12 & 26 & \multirow[t]{2}{*}{0.300} \\
\hline$>1.8 \mathrm{~cm}$ & 21 & 5 & 16 & & 4 & 17 & \\
\hline \multicolumn{8}{|l|}{ Ki-67 } \\
\hline$\leq 4 \%$ & 39 & 19 & 20 & \multirow[t]{2}{*}{0.043} & 14 & 25 & \multirow[t]{2}{*}{0.012} \\
\hline$>4 \%$ & 19 & 4 & 15 & & 1 & 18 & \\
\hline \multicolumn{8}{|l|}{ Mitosis } \\
\hline$<1 / 10 \mathrm{HPF}$ & 43 & 18 & 25 & \multirow[t]{2}{*}{0.762} & 16 & 27 & \multirow[t]{2}{*}{0.003} \\
\hline$\geq 1 / 10 \mathrm{HPF}$ & 16 & 6 & 10 & & 0 & 16 & \\
\hline \multicolumn{8}{|c|}{ Atypical mitosis } \\
\hline with & 9 & 3 & 6 & \multirow[t]{2}{*}{0.725} & 0 & 9 & \multirow[t]{2}{*}{0.097} \\
\hline w/o & 50 & 21 & 29 & & 16 & 34 & \\
\hline \multicolumn{8}{|l|}{ Necrosis } \\
\hline with & 3 & 1 & 2 & \multirow[t]{2}{*}{1.000} & 0 & 3 & \multirow[t]{2}{*}{0.556} \\
\hline w/o & 56 & 23 & 33 & & 16 & 40 & \\
\hline \multicolumn{8}{|l|}{ Nucleoli } \\
\hline with & 9 & 4 & 5 & \multirow{2}{*}{1.000} & 1 & 8 & \multirow[t]{2}{*}{0.421} \\
\hline w/o & 50 & 20 & 30 & & 15 & 35 & \\
\hline Tumor & & & & & & & \\
\hline Carcinoma & 22 & 6 & 16 & 0.106 & 4 & 18 & 0.234 \\
\hline Adenoma & 37 & 18 & 19 & & 12 & 25 & \\
\hline ICP & & & & & & & \\
\hline$\leq 1 \%$ & 49 & 19 & 30 & 0.725 & 13 & 36 & 1.000 \\
\hline$>1 \%$ & 10 & 5 & 5 & & 3 & 7 & \\
\hline
\end{tabular}

HPF, high-power field. Bold indicates statistical significance.

was consistent between parathyroid carcinoma and adenoma $(P=0.234)$. Additionally, PD-L1 expression was not associated with age $(P=0.937)$, sex $(P=0.374)$, tumor size $(P=0.300)$, necrosis $(P=0.556)$, atypical mitosis $(P=0.097)$, nucleoli $(P=0.421)$ or ICP $(P=1.000)$ in the total patient cohort or with survival $(P=0.438)$ in carcinoma patients. However, PD-L1 expression was strongly negatively correlated with the Ki-67 index $(P=0.012)$ and mitosis $(P=0.003)$ in samples when the 22C3 clone was used (Table 3). Similar to the results with the SP263 clone, PD-L1 expression in immune cells was not associated with clinical features or survival $(P=0.739)$ in parathyroid tumor patients when the $22 \mathrm{C} 3$ clone was used (Table 4).

\section{Pairwise comparison of the PD-L1 antibody clones}

Of the 26 carcinoma samples, 5 (19.2\%) were considered positive and 17 (65.4\%) were negative across both antibody clones. The remaining four cases (15.4\%), including three positive cases with the SP263 clone and one positive case with the 22C3 clone, showed inconsistent results (Figs 1A and 4). Of the 37 adenoma cases, 10 (27.0\%) were consistently positive and $17(45.9 \%)$ were consistently negative, whereas the remaining 10 (27.0\%), including eight positive cases with the SP263 clone and two positive cases with the $22 \mathrm{C} 3$ clone, exhibited inconsistent results (Fig. 1B). According to the above results, the consistency between the SP263 and 22C3 clones was only moderate in the total (kappa $=0.520,95 \%$ confidence interval $(C I)=0.412-0.628), \quad$ carcinoma $\quad($ kappa $=0.612, \quad 95 \%$ $\mathrm{CI}=0.439-0.785$ ) and adenoma (kappa $=0.454,95 \%$ $\mathrm{CI}=0.315-0.593$ ) groups (Table 4). Moreover, ICC analysis demonstrated moderate consistency between the SP263 and $22 \mathrm{C} 3$ clones in the total $(\mathrm{ICC}=0.587,95 \% \mathrm{CI}=0.399$ 0.728), carcinoma (ICC $=0.542,95 \% \mathrm{CI}=0.203-0.765$ ) and adenoma $(\mathrm{ICC}=0.625,95 \% \mathrm{CI}=0.381-0.787$ ) groups . However, for immune cells, the consistency between the SP263 and 22C3 clones was excellent (ICC $=0.784,95 \%$ CI $=0.637-0.931)$ (Table 5). https://ec.bioscientifica.com

https://doi.org/10.1530/EC-19-0163
(C) 2019 The authors Published by Bioscientifica Ltd
This work is licensed under a Creative Commons Attribution-NonCommercial 4.0 International License. ded from Bioscientifica.com at 04/26/2023 01:41:36PM via free access 
Table 4 The correlation between clinical features and immune cells PD-L1 expression.

\begin{tabular}{|c|c|c|c|c|c|c|c|}
\hline & \multirow[b]{2}{*}{ Total } & \multicolumn{2}{|c|}{ SP263 (immune cells) } & \multirow[b]{2}{*}{$P$ value } & \multicolumn{2}{|c|}{22 C3 (immune cells) } & \multirow[b]{2}{*}{$P$ value } \\
\hline & & Positive & Negative & & Positive & Negative & \\
\hline \multicolumn{8}{|l|}{ Gender } \\
\hline M & 24 & 1 & 23 & \multirow{2}{*}{0.639} & 0 & 24 & \multirow[t]{2}{*}{0.138} \\
\hline $\mathrm{F}$ & 35 & 4 & 31 & & 4 & 31 & \\
\hline \multicolumn{8}{|l|}{ Age } \\
\hline$\leq 50$ years & 30 & 3 & 27 & \multirow[t]{2}{*}{1.000} & 2 & 28 & \multirow[t]{2}{*}{1.000} \\
\hline$>50$ years & 29 & 2 & 27 & & 2 & 27 & \\
\hline \multicolumn{8}{|l|}{ Diameter } \\
\hline$\leq 1.8 \mathrm{~cm}$ & 38 & 4 & 34 & \multirow[t]{2}{*}{0.646} & 4 & 34 & \multirow[t]{2}{*}{0.286} \\
\hline$>1.8 \mathrm{~cm}$ & 21 & 1 & 20 & & 0 & 21 & \\
\hline \multicolumn{8}{|l|}{$\mathrm{Ki}-67$} \\
\hline$\leq 4 \%$ & 39 & 2 & 37 & \multirow[t]{2}{*}{0.318} & 2 & 37 & \multirow[t]{2}{*}{0.591} \\
\hline$>4 \%$ & 19 & 3 & 16 & & 2 & 17 & \\
\hline \multicolumn{8}{|l|}{ Mitosis } \\
\hline$<1 / 10$ HPF & 43 & 3 & 40 & \multirow[t]{2}{*}{0.606} & 2 & 41 & \multirow[t]{2}{*}{0.295} \\
\hline$\geq 1 / 10 \mathrm{HPF}$ & 16 & 2 & 14 & & 2 & 14 & \\
\hline \multicolumn{8}{|c|}{ Atypical mitosis } \\
\hline with & 9 & 2 & 7 & \multirow[t]{2}{*}{0.163} & 2 & 7 & \multirow[t]{2}{*}{0.106} \\
\hline w/o & 50 & 3 & 47 & & 2 & 48 & \\
\hline \multicolumn{8}{|l|}{ Necrosis } \\
\hline with & 3 & 1 & 2 & \multirow[t]{2}{*}{0.237} & 1 & 2 & \multirow[t]{2}{*}{0.193} \\
\hline w/o & 56 & 4 & 52 & & 3 & 53 & \\
\hline \multicolumn{8}{|l|}{ Nucleoli } \\
\hline with & 9 & 1 & 8 & \multirow[t]{2}{*}{0.577} & 1 & 8 & \multirow[t]{2}{*}{0.494} \\
\hline w/o & 50 & 4 & 46 & & 3 & 47 & \\
\hline \multicolumn{8}{|l|}{ Tumor } \\
\hline Carcinoma & 22 & 3 & 19 & \multirow[t]{2}{*}{0.351} & 2 & 20 & 0.624 \\
\hline Adenoma & 37 & 2 & 35 & & 2 & 35 & \\
\hline
\end{tabular}

\section{Discussion}

Parathyroid adenoma accounts for $85 \%$ of primary hyperparathyroidism cases; however, parathyroid carcinoma is fairly rare, accounting for no more than $5 \%$ of primary hyperparathyroidism cases (18). The age of our patients was coincident with the previous data, and the peak incidence of parathyroid carcinoma and adenoma occurred among patients aged 50-60 years $(18,19)$. The female:male ratio of carcinoma and adenoma were different according to our results. As reported previously, the female:male ratio of carcinoma was nearly $1: 1$, while that of adenoma was 2-3:1 (18). The tumor size of both carcinoma and adenoma varied in our study, as researchers have noted previously (18). Furthermore, according to previous studies, the Ki-67 index and mitotic rate are much higher in carcinomas than in adenomas; however, there was substantial overlap between these groups (20). Atypical mitosis and nucleoli were more frequent in carcinomas than in adenomas in our series, but these criteria are not reliable for diagnosing malignancies (18). Moreover, the follow-up information indicated that most carcinoma patients experienced relapses and metastasis with persistent hyperparathyroidism. And the majority of carcinoma patients underwent more than one resection. Similar to carcinoma, a previous study demonstrated that recurrent and persistent hyperparathyroidism also appeared in a subset of adenoma patients, especially those with parathyromatosis (21). Although the survival of these patients was relatively long compared with that of patients with other malignancies (19), the quality of their lives was disrupted by the disease. Thus, except for controlling hypercalcemia by drugs, we must also try to decrease the tumor burden by chemical treatment or surgery.

This study is the first to examine and report PD-L1 expression in parathyroid adenoma and carcinoma. Numerous studies have revealed PD-L1 expression in endocrine tumors, including pituitary tumors (11), papillary thyroid carcinomas $(12,13)$, adrenocortical carcinomas (14), pheochromocytomas (15) and gastroenteropancreatic neuroendocrine neoplasms (16). However, these studies demonstrated that this variable had significance. In our study, tumor cell PD-L1 expression was less than $10 \%$ in more than $90 \%$ of the samples and was less than $1 \%$ in more than half of the samples, regardless https://ec.bioscientifica.com

https://doi.org/10.1530/EC-19-0163 (c) 2019 The authors Published by Bioscientifica Ltd
This work is licensed under a Creative Commons Attribution-NonCommercial 4.0 International License. ded from Bioscientifica.com at 04/26/2023 01:41:36PM via free access 


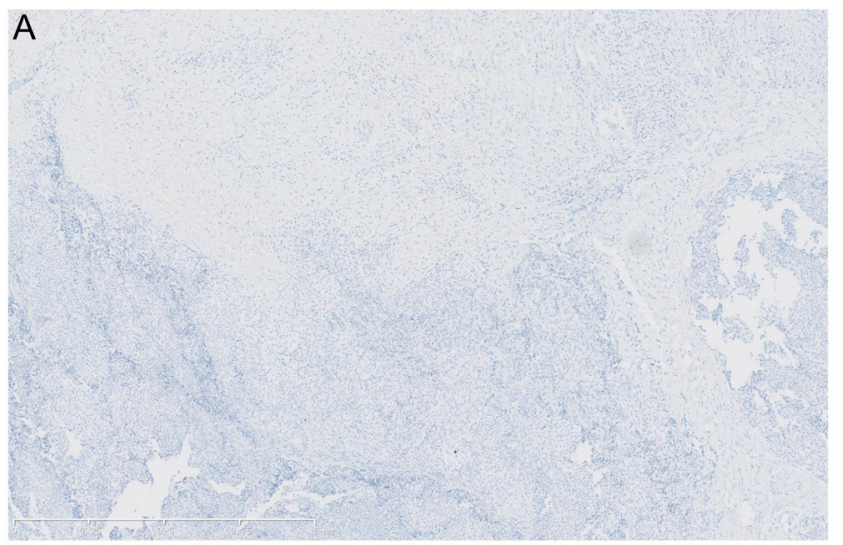

B

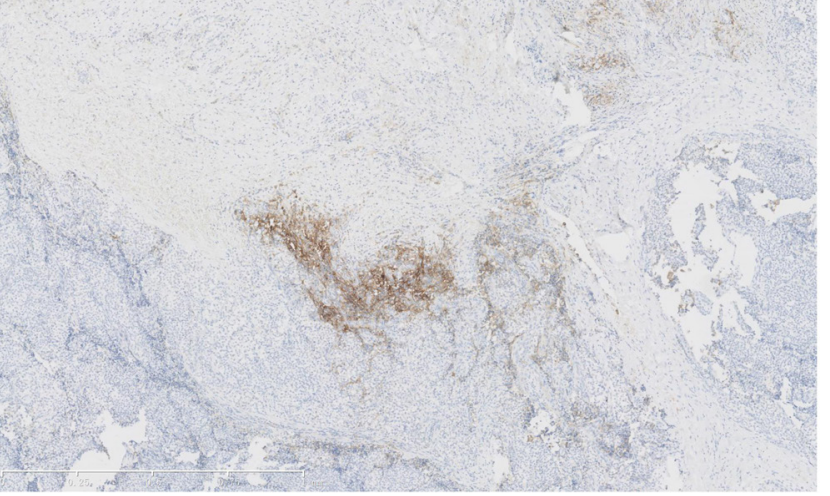

Figure 4

A case with inconsistent PD-L1 staining between the SP263 (A, 50x) and $22 \mathrm{C3}(\mathrm{B}, 50 \times)$ antibody clones.

of whether the SP263 clone or the 22C3 clone was used. In a current study about medullary thyroid carcinoma, the results demonstrated that PD-L1 expression in either tumor cells or tumor-infiltrating immune cells was very low (22). The researchers explained that the reason may be that medullary thyroid carcinoma is one of the solid tumors with a low mutation load and neoantigen repertoire (22). In addition, medullary carcinoma exhibits very few tumor-infiltrating immune cells, which was

Table 5 Pairwise comparisons of SP263 and 22C3 clones.

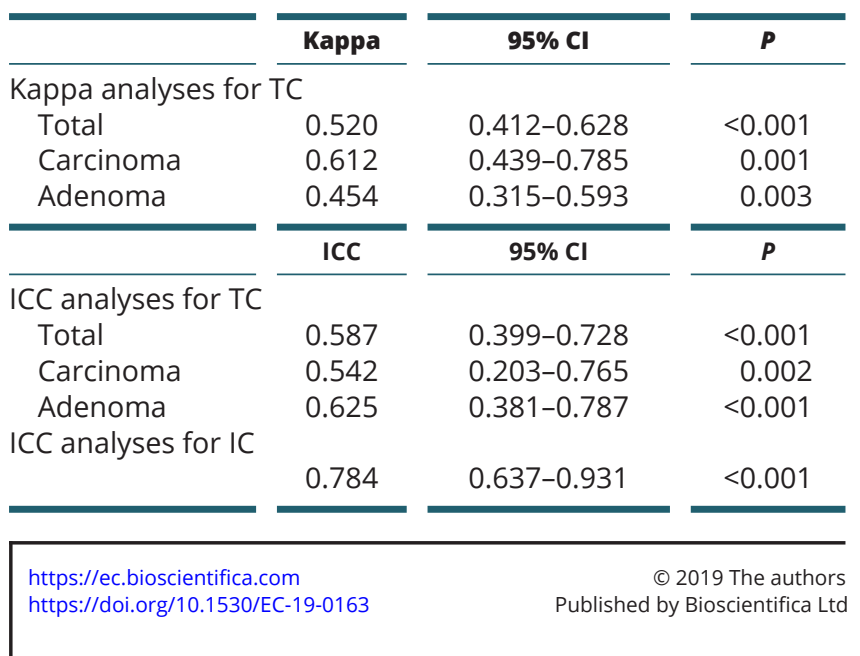

the other hypothesis proposed to explain this very low PD-L1 expression (22). Previous studies have showed that tumor-infiltrating immune cells are correlated with tumor cell PD-L1 expression $(17,23)$. As in medullary thyroid carcinoma, tumor-infiltrating immune cells are scant in parathyroid tumors. Furthermore, we also investigated MMR-related proteins (MLH-1, MSH-2, MSH-6 and PMS2) to evaluate the MMR status of parathyroid tumors and demonstrated that all the cases in our series were pMMR, which indicated that parathyroid tumors have low mutational loads and neoantigen repertoires. Unfortunately, the lack of either PD-L1 expression or mutational loads indicates the limited effectiveness of immunotherapy.

Concerning tumor-infiltrating immune cells, according to current studies, the quantity of tumorinfiltrating immune cells is associated with PD-L1 expression as well as tumor mutational burden (TMB) $(23,24)$. Furthermore, tertiary lymphoid structures (TLSs) are also a histological feature that could predict PD-L1 expression and prognosis (17). However, we did not find a relationship between tumor cell PD-L1 expression and tumor-infiltrating immune cells in parathyroid tumors, possibly because of a deficiency of tumor-infiltrating immune cells in parathyroid tumors. Furthermore, previous studies demonstrated that PD-L1 expression in tumor-infiltrating immune cells reflected survival and the effectiveness of immunotherapy $(25,26,27)$. Additionally, there are two ways to evaluate immune cell PD-L1 expression. In gastric and pulmonary carcinoma, tumor-infiltrating immune cell PD-L1 expression is scored as a ratio of positive immune cells of all tumor cells (10, 28), and in urothelial carcinoma, which is scored as a percentage of positive immune cells within the tumor area (9). Because of the deficiency of tumor-infiltrating immune cells in parathyroid tumors, we decided to evaluated immune cell PD-L1 expression as in urothelial carcinoma, which could magnify the difference between individuals. However, the immune cell PD-L1 expression was fairly low in most parathyroid tumors. In addition, although immune cell PD-L1 expression is related to the effectiveness of immunotherapy in pulmonary, gastric and urothelial carcinoma $(9,10,28)$, our research did not demonstrate any relationship between immune cell PD-L1 expression and the clinical features or survival of parathyroid tumor patients, which may be caused by the rarity of positive cases. Combined the results mentioned above, the lack of immune cells and PD-L1 positive immune cells makes the use of immunotherapy in parathyroid tumors unlikely. 
In a series of malignant tumors, PD-L1 expression was increased in the tumor cells $(16,29,30)$. In addition, according to previous research about thyroid carcinoma, PD-L1 was highly expressed in a subset of patients with advanced cancer (13). In contrast, regarding PD-L1 expression in parathyroid tumors, our series showed no significant difference between carcinoma and adenoma. However, we found that PD-L1 expression was associated with the Ki-67 index, which is an adjunct factor for distinguishing benign from malignant tumors. Moreover, regarding the samples tested with the 22C3 clone, PD-L1 expression was negatively correlated with mitosis, which is an important factor for predicting malignancy. These indicate that tumor cell PD-L1 expression probably has potential to distinguish benign and malignant tumors, but its effectiveness still need more data to evaluate.

According to our study, the consistency between the SP263 and 22C3 clones was worse in parathyroid tumors than in other malignancies $(9,10)$. Although the related staining procedures were different between these antibody clones, the current researches have proved that their staining results demonstrated excellent consistency in pulmonary and urothelial carcinoma $(9,10)$. Additionally, either the antibody clones or their related staining procedures are approved by FDA, which ensures the staining results are repeatable and stable. However, the results of our research demonstrated that PD-L1 staining in parathyroid tumor cells relied greatly on the antibody clone used, most likely due to the different structure of the PD-L1 protein in parathyroid tumors. However, this hypothesis needs to be verified. In contrast, for the evaluation of PD-L1 expression in tumor-infiltrating immune cells, these two clones demonstrated excellent consistency. The pairwise comparisons indicated that the consistency between the different PD-L1 antibodies most likely depended greatly on the types of tumors or cells investigated.

\section{Conclusion}

We used FDA-approved, commercially available materials and procedures to stain and evaluate the PD-L1 expression in parathyroid tumors for the first time. PD-L1 expression in both tumor cells and immune cells was deficient in the majority of parathyroid tumors, which indicates the limited effectiveness of immunotherapy. Additionally, the consistency between the SP263 and 22C3 clones in parathyroid tumors was worse than that in other malignancies, indicating that the consistency between different PD-L1 antibodies depends greatly on the types of tumors or cells investigated.

\section{Declaration of interest}

The authors declare that there is no conflict of interest that could be perceived as prejudicing the impartiality of the research reported.

\section{Funding}

This study is supported by Chinese Academy of Medical Science (CAMS) Initiative for Innovative Medicine (2017-12M-2-001).

\section{References}

1 Nishino M, Ramaiya NH, Hatabu H \& Hodi FS. Monitoring immune-checkpoint blockade: response evaluation and biomarker development. Nature Reviews: Clinical Oncology 201714 655-668. (https://doi.org/10.1038/nrclinonc.2017.88)

2 Robert C, Schachter J, Long GV, Arance A, Grob JJ, Mortier L, Daud A, Carlino MS, McNeil C, Lotem M, et al. Pembrolizumab versus ipilimumab in advanced melanoma. New England Journal of Medicine 2015372 2521-2532. (https://doi.org/10.1056/NEJMoa1503093)

3 Borghaei H, Paz-Ares L, Horn L, Spigel DR, Steins M, Ready NE, Chow LQ, Vokes EE, Felip E, Holgado E, et al. Nivolumab versus docetaxel in advanced nonsquamous non-small-cell lung cancer. New England Journal of Medicine 2015373 1627-1639. (https://doi. org/10.1056/NEJMoa1507643)

4 Brahmer J, Reckamp KL, Baas P, Crino L, Eberhardt WE, Poddubskaya E, Antonia S, Pluzanski A, Vokes EE, Holgado E, et al. Nivolumab versus docetaxel in advanced squamous-cell non-smallcell lung cancer. New England Journal of Medicine 2015373 123-135. (https://doi.org/10.1056/NEJMoa1504627)

5 Prasad V, Kaestner V \& Mailankody S. Cancer drugs approved based on biomarkers and not tumor type-FDA approval of pembrolizumab for mismatch repair-deficient solid cancers. JAMA Oncology 20184 157-158. (https://doi.org/10.1001/jamaoncol.2017.4182)

6 Langer CJ, Gadgeel SM, Borghaei H, Papadimitrakopoulou VA, Patnaik A, Powell SF, Gentzler RD, Martins RG, Stevenson JP, Jalal SI, et al. Carboplatin and pemetrexed with or without pembrolizumab for advanced, non-squamous non-small-cell lung cancer: a randomised, phase 2 cohort of the open-label KEYNOTE-021 study. Lancet Oncology 201617 1497-1508. (https://doi.org/10.1016/S14702045(16)30498-3)

7 Garon EB, Rizvi NA, Hui R, Leighl N, Balmanoukian AS, Eder JP, Patnaik A, Aggarwal C, Gubens M, Horn L, et al. Pembrolizumab for the treatment of non-small-cell lung cancer. New England Journal of Medicine 2015372 2018-2028. (https://doi.org/10.1056/ NEJMoa1501824)

8 Reck M, Rodriguez-Abreu D, Robinson AG, Hui R, Csoszi T, Fulop A, Gottfried M, Peled N, Tafreshi A, Cuffe S, et al. Pembrolizumab versus chemotherapy for PD-L1-positive non-small-cell lung cancer. New England Journal of Medicine 2016375 1823-1833. (https://doi. org/10.1056/NEJMoa1606774)

9 Hodgson A, Slodkowska E, Jungbluth A, Liu SK, Vesprini D, Enepekides D, Higgins K, Katabi N, Xu B \& Downes MR. PD-L1 immunohistochemistry assay concordance in urothelial carcinoma of the bladder and hypopharyngeal squamous cell carcinoma. American Journal of Surgical Pathology 201842 1059-1066. (https:// doi.org/10.1097/PAS.0000000000001084)

10 Tsao MS, Kerr KM, Kockx M, Beasley MB, Borczuk AC, Botling J, Bubendorf L, Chirieac L, Chen G, Chou TY, et al. PD-L1 immunohistochemistry comparability study in real-life clinical samples: results of blueprint phase 2 project. Journal of Thoracic 
Oncology 201813 1302-1311. (https://doi.org/10.1016/j. jtho.2018.05.013)

11 Mei Y, Bi WL, Greenwald NF, Du Z, Agar NY, Kaiser UB, Woodmansee WW, Reardon DA, Freeman GJ, Fecci PE, et al. Increased expression of programmed death ligand 1 (PD-L1) in human pituitary tumors. Oncotarget 20167 76565-76576. (https:// doi.org/10.18632/oncotarget.12088)

12 Bai Y, Niu D, Huang X, Jia L, Kang Q, Dou F, Ji X, Xue W, Liu Y, Li Z, et al. PD-L1 and PD-1 expression are correlated with distinctive clinicopathological features in papillary thyroid carcinoma. Diagnostic Pathology 201712 72. (https://doi.org/10.1186/s13000017-0662-z)

13 Chowdhury S, Veyhl J, Jessa F, Polyakova O, Alenzi A, MacMillan C, Ralhan R \& Walfish PG. Programmed death-ligand 1 overexpression is a prognostic marker for aggressive papillary thyroid cancer and its variants. Oncotarget $2016732318-32328$. (https://doi.org/10.18632/ oncotarget.8698)

14 Fay AP, Signoretti S, Callea M, Telomicron GH, McKay RR, Song J, Carvo I, Lampron ME, Kaymakcalan MD, Poli-de-Figueiredo CE, et al. Programmed death ligand-1 expression in adrenocortical carcinoma: an exploratory biomarker study. Journal for ImmunoTherapy of Cancer 20153 3. (https://doi.org/10.1186/s40425-015-0047-3)

15 Pinato DJ, Black JR, Trousil S, Dina RE, Trivedi P, Mauri FA \& Sharma R. Programmed cell death ligands expression in phaeochromocytomas and paragangliomas: relationship with the hypoxic response, immune evasion and malignant behavior. Oncoimmunology 20176 e1358332. (https://doi.org/10.1080/21624 02X.2017.1358332)

16 Cavalcanti E, Armentano R, Valentini AM, Chieppa M \& Caruso ML. Role of PD-L1 expression as a biomarker for GEP neuroendocrine neoplasm grading. Cell Death and Disease 20178 e3004. (https://doi. org/10.1038/cddis.2017.401)

17 Mlecnik B, Bindea G, Angell HK, Maby P, Angelova M, Tougeron D, Church SE, Lafontaine L, Fischer M, Fredriksen T, et al. Integrative analyses of colorectal cancer show immunoscore is a stronger predictor of patient survival than microsatellite instability. Immunity $2016 \mathbf{4 4}$ 698-711. (https://doi.org/10.1016/j. immuni.2016.02.025)

18 Lloyd RV, Osamura RY, Klöppel G \& Rosai J. WHO Classification of Tumors of Endocrine Organs. Lyon, France: World Health Organization, 2017.

19 Lee PK, Jarosek SL, Virnig BA, Evasovich M \& Tuttle TM. Trends in the incidence and treatment of parathyroid cancer in the United States. Cancer 2007109 1736-1741. (https://doi.org/10.1002/ cncr.22599)

20 Fernandez-Ranvier GG, Khanafshar E, Tacha D, Wong M, Kebebew E, Duh QY \& Clark OH. Defining a molecular phenotype for benign and malignant parathyroid tumors. Cancer 2009115 334-344. (https://doi.org/10.1002/cncr.24037)
21 Hage MP, Salti I \& El-Hajj Fuleihan G. Parathyromatosis: a rare yet problematic etiology of recurrent and persistent hyperparathyroidism. Metabolism: Clinical and Experimental $20126 \mathbf{6 1}$ 762-775. (https://doi.org/10.1016/j.metabol.2011.11.001)

22 Bongiovanni M, Rebecchini C, Saglietti C, Bulliard JL, Marino L, de Leval L \& Sykiotis GP. Very low expression of PD-L1 in medullary thyroid carcinoma. Endocrine-Related Cancer 201724 L35-L38. (https://doi.org/10.1530/ERC-17-0104)

23 Schalper KA.PD-L1 expression and tumor-infiltrating lymphocytes: revisiting the antitumor immune response potential in breast cancer. Oncoimmunology 20143 e29288. (https://doi.org/10.4161/ onci.29288)

24 Spigel DR, Schrock AB, Fabrizio D, Frampton GM, Sun J, He J, Gowen K, Johnson ML, Bauer TM, Kalemkerian GP, et al. Total mutation burden (TMB) in lung cancer (LC) and relationship with response to PD-1/PD-L1 targeted therapies. Journal of Clinical Oncology 201634 9017. (https://doi.org/10.1200/JCO.2016.34.15_ suppl.9017)

25 Herbst RS, Soria JC, Kowanetz M, Fine GD, Hamid O, Gordon MS, Sosman JA, McDermott DF, Powderly JD, Gettinger SN, et al. Predictive correlates of response to the anti-PD-L1 antibody MPDL3280A in cancer patients. Nature 2014515 563-567. (https:// doi.org/10.1038/nature14011)

26 Rakaee M, Kilvaer TK, Dalen SM, Richardsen E, Paulsen EE, Hald SM, Al-Saad S, Andersen S, Donnem T, Bremnes RM, et al. Evaluation of tumor-infiltrating lymphocytes using routine H\&E slides predicts patient survival in resected non-small cell lung cancer. Human Pathology 201879 188-198. (https://doi.org/10.1016/j. humpath.2018.05.017)

27 Tumeh PC, Harview CL, Yearley JH, Shintaku IP, Taylor EJ, Robert L, Chmielowski B, Spasic M, Henry G, Ciobanu V, et al. PD-1 blockade induces responses by inhibiting adaptive immune resistance. Nature 2014515 568-571. (https://doi.org/10.1038/nature13954)

28 Muro K, Chung HC, Shankaran V, Geva R, Catenacci D, Gupta S, Eder JP, Golan T, Le DT, Burtness B, et al. Pembrolizumab for patients with PD-L1-positive advanced gastric cancer (KEYNOTE-012): a multicentre, open-label, phase 1b trial. Lancet: Oncology 201617 717-726. (https://doi.org/10.1016/S1470-2045(16)00175-3)

29 Koh J, Go H, Keam B, Kim MY, Nam SJ, Kim TM, Lee SH, Min HS, Kim YT, Kim DW, et al. Clinicopathologic analysis of programmed cell death-1 and programmed cell death-ligand 1 and 2 expressions in pulmonary adenocarcinoma: comparison with histology and driver oncogenic alteration status. Modern Pathology 201528 1154-1166. (https://doi.org/10.1038/modpathol.2015.63)

30 Shimoji M, Shimizu S, Sato K, Suda K, Kobayashi Y, Tomizawa K, Takemoto T \& Mitsudomi T. Clinical and pathologic features of lung cancer expressing programmed cell death ligand 1 (PDL1). Lung Cancer 201698 69-75. (https://doi.org/10.1016/j. lungcan.2016.04.021)

Received in final form 16 May 2019

Accepted 6 June 2019 https://ec.bioscientifica.com https://doi.org/10.1530/EC-19-0163
(C) 2019 The authors Published by Bioscientifica Ltd

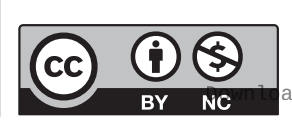

This work is licensed under a Creative Commons Attribution-NonCommercial 4.0 International License. ded from Bioscientifica.com at 04/26/2023 01:41:36PM 